\title{
Os índios do Ceará na Confederação do Equador
}

The natives of Ceará in the confederation of the Equator

\author{
João Paulo Peixoto Costa*
}

\section{Resumo}

Este artigo discute o envolvimento político e militar dos índios do Ceará na Confederação do Equador de 1824. Nesse conflito, seu posicionamento em relação ao imperador do Brasil dependeu bastante da conjuntura cearense frente à nacional. Se tradicionalmente era reconhecida sua devoção ao monarca, índios e suas lideranças contestaram as políticas de Pedro I que cerceavam sua liberdade. Em tais situações de confronto bélico é possível refletir acerca dos significados indígenas de vassalos e cidadãos brasileiros, neste caso, com base nas ideias do liberalismo por eles apropriadas e em seu antilusitanismo particular. A política dos índios nesse contexto, que dialogava elementos tradicionais com preceitos liberais, lidava com a discriminação dos não índios, o anseio de autonomia das elites locais e o autoritarismo da Coroa, em meio a mudanças nos estatutos legais que cada vez mais ameaçavam suas condições de trabalho e a preservação de suas terras.

Palavras-chave: índios; guerra; política, Ceará.

\section{Abstract}

This article reflects on the political and military involvement of the native people of Ceará in the Confederation of the Equator, in 1824. In such a conflict, their position in relation to the emperor of Brazil depended a lot on the situation of the province of Ceará regarding the national political situation. In a context of warlike confrontation, it is possible to reflect on the indigenous meanings of Brazilian vassals and citizens and the relations they established with non-Indians and governments, in the midst of changes in their legal statutes that increasingly threatened their working conditions and preservation of their land.

Keywords: Indians; war; politics, Ceará.

\footnotetext{
* Instituto Federal do Piauí (IFPI). Teresina, PI, Brasil. joão.peixoto@ifpi.edu.br
} 
Os chefes indianos (sic), assim como a gente que deles dependia, foram de grande préstimo na restauração da ordem ... formando, com efeito, os melhores padrões da raça nativa que eu vira na América do Sul.

(Cochrane, 1856, p.184-185)

Apesar do curto período que separou a Revolução Pernambucana de 1817 e a Confederação do Equador em 1824, nele as capitanias do norte do Brasil vivenciaram intensas transformações políticas e experiências de participação popular. Após a insurreição liberal-republicana que pretendeu separá-los do corpo de súditos do rei de Portugal, os habitantes do Brasil tiveram de lidar com as transformações provocadas pelos liberais do Porto, em 1820. No ano seguinte, as Cortes reunidas em Lisboa exigiram o retorno da família real para a Europa e submeteram o monarca a uma Constituição, promovendo a descentralização do poder no império. Os planos portugueses de recolonização do Brasil, no entanto, motivaram a dissolução do Reino Unido e a criação do novo Estado soberano no lugar da antiga América lusitana em 1822. Apesar disso, as ideias liberais difundidas pelas Cortes de diminuir a concentração do poder nas mãos do rei foram bem recebidas pelas autoridades provinciais brasileiras. A independência do Brasil, portanto, foi marcada por disputas de projetos e interesses locais, em que a adesão de cada circunscrição administrativa ao Rio de Janeiro se deu por motivos próprios.

Em contrapartida, a concentração de poder pelas elites desagradava muita gente. Para os índios, o liberalismo provincial e o encolhimento da figura do rei podiam significar o uso abusivo e ilimitado de sua mão de obra e a usurpação de suas terras por parte dos poderosos proprietários rurais. No Ceará, o apoio indígena ao grupo político do interior - em oposição ao da capital - durante a separação política brasileira não se deu necessariamente por afinidade ideológica. Em 1822 e 1823, os líderes sertanejos e os índios tinham inimigos comuns: a elite de Fortaleza e os portugueses, representantes das ideias que defendiam o acúmulo do poder nas capitais provinciais. Por isso, mal proclamada a independência do Brasil, as ações centralizadoras do recém-coroado imperador Pedro I passaram a provocar insatisfação. Em março de 1823, a vila da Fortaleza de Nossa Senhora da Assunção foi erigida à categoria de cidade, ${ }^{1}$ sendo "mais uma medida tomada pelo imperador com o objetivo de ter as capitais ... sob seu domínio", como afirma Keile Felix (2010, p.102). Com isso, o monarca visava conquistar a adesão das câmaras mais importan- 
tes de cada província aos seus planos de concentração de poder, o que não agradou aos grupos políticos do interior cearense que, no fim do ano anterior, haviam se garantido no governo da província, com apoio, também, dos índios.

A oposição a Pedro I ganhou ainda mais força quando, em novembro de 1823, ele dissolveu a Assembleia Constituinte. Entre o fim desse ano e o início de 1824, o monarca propôs um novo projeto de Constituição - trazendo como novidade o famigerado poder moderador - e nomeou novos presidentes para as províncias, abolindo os governos eleitos localmente. As crescentes tensões entre a Corte no Rio de Janeiro e as autoridades em Pernambuco culminaram, em julho de 1824, com a proclamação da Confederação de Equador, tendo a adesão do Ceará ocorrido no fim do mês de agosto.

Como afirma Denis Bernardes, as diferenças substanciais entre os dois movimentos insurrecionais iniciados em território pernambucano estavam no fato de que, em 1817, "ainda vigorava sobre o espaço brasileiro o poder de uma monarquia absoluta, apegada à cultura do Antigo Regime”, ao passo que, em "1824, o quadro era outro e havia conhecido profundas mudanças". Prova disso, como Bernardes observa, é que, apesar de diversas experiências políticas, princípios e participantes terem estado presentes nesses dois momentos, muitos dos envolvidos na primeira rebelião encontravam-se em lados opostos na segunda (Bernardes, 2011, p.133-134).

Um exemplo no Ceará foi a história da família Alencar. José Martiniano e seu irmão Tristão Gonçalves lideraram, em 1817, o movimento republicano no Crato, rompendo laços com a Coroa, e foram derrotados após 8 dias por José Pereira Filgueiras. Em 1822, os antigos inimigos se aliaram para destituir a junta governativa cearense, acusada de ser excessivamente "portuguesa", e derrotar o comandante Joaquim José da Cunha Fidié no Maranhão no ano seguinte, em defesa de Pedro I. Por conta da dissolução da Constituinte, os antigos defensores do monarca passaram a ser seus acérrimos opositores. Nesses conflitos havia, segundo Bernardes (2011, p.147), a "existência de uma dinâmica local que, embora não desvinculada dos processos políticos mais amplos, não estava, necessariamente, alinhada às decisões ou legitimações institucionais". Apesar das mudanças de lado, em todos esses momentos estavam os anseios das elites locais pelo poder. O apoio ou não ao soberano ou a determinadas correntes de pensamento dependia de contra quem rivalizavam e do contexto político do Brasil.

Para Denis Bernardes, a contestação do absolutismo no império português e a reestruturação do pacto que fundara a nação e dera legitimidade ao 
rei a partir das Cortes instauravam "uma nova ordem política e social”. Assim, "cada categoria social, cada fração da sociedade, cada identidade e interesse étnico, econômico, religioso e mais que fosse, buscou afirmar suas reivindicações, buscou assegurar um lugar no novo pacto" (Bernardes, 2011, p.137). Por isso que não apenas as elites político-econômicas, mas também os grupos populares participaram com intensidade das lutas políticas que marcaram a formação do Estado nacional brasileiro.

As tropas indígenas do Ceará também estiveram presentes nos embates de 1824. Para eles, a defesa do imperador, em conexão com a manutenção de suas garantias, foi uma constante com poucas variações. A mesma postura foi notada entre os indígenas de outras províncias (cf. Mello, 2004, p.233; Carvalho, 2002, p.78; Bernardes, 2011, p.154; Dantas, 2015, p.132). A peculiaridade dos índios do Ceará foi que, pela primeira vez, estiveram ao lado daqueles que se opuseram às políticas reais, ao menos num momento inicial. A defesa do imperador, ainda que afinal tenha prevalecido, conviveu com outras variantes, relativas à sua postura frente aos interesses das elites locais e às formas como estas se posicionavam diante de suas demandas.

\section{“TEMOS POR BRASÃO O ARCO E A FLECHA”}

Em dezembro de 1823, José Martiniano de Alencar - que passara da condição de preso político em 1817 a deputado na Assembleia Constituinte - deixou o Rio de Janeiro em direção ao Ceará. Na passagem pelo Recife, tomou conhecimento da reunião do Grande Conselho que empossara Manuel de Carvalho Paes de Andrade como presidente e que exigia uma nova Constituinte. Segundo Evaldo Cabral de Mello, Carvalho enviou Alencar ao território cearense "com a tarefa de organizar apoio à luta pela reconvocação" (Mello, 2004, p.166). De acordo com Torres Câmara, as notícias foram logo difundidas, "com grande escândalo, às câmaras da província", tomadas de uma "irritação sem limites" e do "espírito de revolta que lavrava entre os patriotas" (Câmara, 1924, p.309-310).

Em janeiro de 1824, as câmaras de Quixeramobim e do Icó chegaram a proclamar a república, e em outras vilas, ainda que não tenham feito o mesmo, os vereadores manifestaram sua insatisfação em relação à política adotada pelo imperador. De igual forma, o governo da província do Ceará protestou contra a centralização de Pedro I mediante ofício em 31 de março (cf. Câmara, 1924, 
p.310-311; Pinto, 1899, p.35-36; Peixoto, 1907, p.39-40; Girão, 1984, p.135-136; Felix, 2010, p.97-100; Mello, 2004, p.190). No dia 14 de abril as tensões aumentaram ainda mais quando Pedro José da Costa Barros, presidente nomeado da província, aportou em Fortaleza. Com apoio da Câmara da capital, Costa Barros foi empossado, provocando a fuga do antigo governo interino para Arronches. Após alguns dias recrutando adeptos, as lideranças depostas - tendo à frente Tristão Gonçalves e Pereira Filgueiras - montaram um quartel-general em Messejana e, no dia 29, depuseram o presidente nomeado e tomaram à força o governo da província (cf. Pinto, 1899, p.35-36; Nogueira, 1890, p.53; Peixoto, 1907, p.41-42; Câmara, 1924, p.313-317; Studart, 1924a, p.613-614; Girão, 1984, p.136-137; Felix, 2010, p.97-104; Mello, 2004, p.190).

O que a historiografia não observou é que as duas vilas que serviram de suporte militar aos liberais para a ação de retomada do poder no Ceará eram de índios. Guilherme Studart notou que a valia de Gonçalves e Filgueiras "crescera entre o povo pelos triunfos que haviam colhido na campanha contra Fidié" (Studart, 1924a, p.614). Para os índios, entretanto, os motivos para a aliança com esses dois líderes eram bem mais profundos: Gonçalves e Filgueiras atuaram na libertação dos presos do motim indígena de Maranguape de 1822 (cf. Costa, 2016, p.124-138; Xavier, 2015, p.82-98) e encabeçaram a destituição da antiga junta de governo que reprimira com tanta violência os amotinados indígenas (Costa, 2016, p.257). Pouco se falou sobre a composição da tropa que submeteu a Câmara de Fortaleza e destituiu Costa Barros, mas era bem provável que fosse formada, em grande parte, por índios dessas duas vilas. ${ }^{2}$

As ações dos liberais, "com ampla participação das mais diversas camadas sociais, inclusive da gente do povo", baseavam-se na crença de que Portugal supostamente planejava uma recolonização do país recém-independente em associação com Pedro I (Bernardes, 2011, p.147-148). Tais rumores se originaram, por sua vez, do bloqueio naval no Recife imposto pelo imperador no início de maio de 1824, em represália às negativas de Pernambuco em aceitar o presidente nomeado (cf. Mello, 2004, p.191).

O governo do Ceará reagiu firmemente às ações repressivas do imperador no Recife, associando-as também a uma traição do monarca, acusado de estar voltado aos interesses do absolutismo português. No ofício do dia 18 de maio o então presidente Tristão Gonçalves escreveu aos diretores das vilas de índios, ordenando-os a armar seus subordinados. Para Gonçalves, nas condições do contexto em que escrevia, não haveria "brasileiro tão infame que preferi[sse] o cativeiro à liberdade", e estava certo de que "os índios, meus valorosos patrí- 
cios, não querem ser escravos”. Por isso, exigiu que cada indígena estivesse pronto com " 50 flechas e dois arcos ao primeiro aceno da invasão da Europa, desse Portugal orgulhoso só, que nos tem abismado há mais de 300 anos no mais ignominioso estado. Vossa mercê avise aos nossos irmãos dos seus deveres, e plenamente execute o que aqui se lhe ordena". ${ }^{3}$

É curiosa a maneira irmanada de Gonçalves tratar os indígenas. Há em seu texto tanto o reconhecimento pelo apoio recebido desses grupos nas duas vezes que chegara ao governo - em dezembro de 1822 e abril de 1824 - quanto a busca por consolidar essa aliança. Por isso, não é à toa que, tratando-os como irmãos da mesma pátria, o inimigo apontado é "Portugal", que tentava novamente escravizá-los, e não o imperador, que nem ao menos foi citado. Além disso, o argumento utilizado para insuflá-los contra essa "invasão orgulhosa" da Europa era justamente algo muito caro nas demandas indígenas: a busca por sua liberdade. De fato, como aponta a historiografia, antes de proclamarem a Confederação do Equador, os líderes não falavam em "separação", "república" ou nada que pusesse em xeque diretamente a figura do imperador. As reclamações se encontravam, portanto, muito mais nas atitudes do que na própria figura do soberano: as críticas a Pedro I não visavam sua deposição, mas que ele agisse de acordo com uma monarquia constitucional (cf. Mello, 2004, p.182-183; Bernardes, 2011, p.151-152).

Nas comunicações feitas aos índios do Ceará, Gonçalves era bastante cuidadoso. Por um lado, não citava o imperador, indicando Portugal como inimigo; por outro, sabendo da reciprocidade que havia na histórica relação de vassalagem entre essa população e a Coroa portuguesa, o presidente procurou, também ele, se representar como benfeitor para os indígenas. Respondendo a ofício do diretor de Arronches, Gonçalves solicitou ao capitão-mor da vila em 21 de maio uma "relação circunstanciada dos postos vagos das suas ordenanças e daqueles oficiais que servem sem título competente". ${ }^{4}$ As atitudes do presidente não eram altruístas, decorrendo da lei de 1823 que estabelecera a promoção das patentes de ordenança como competência provincial. Mas serviram como estratégia para Gonçalves, que levava em conta o já conhecido apreço indígena pelo serviço militar e das lideranças por seus títulos. O presidente buscava, ao atender o ofício do diretor, beneficiar os oficiais e sutilmente substituir o imperador na função de provedor.

Tal medida, em atendimento aos oficiais indígenas de Arronches, ocorreu poucos dias depois do armamento geral dos índios promovido diante da possível invasão lusitana, como vimos há pouco. As ações do presidente também 
se somavam ao antilusitanismo indígena do período, que tinha origem em sua oposição às Cortes de Lisboa. Desde 1821, os índios temiam que a Constituição portuguesa, após ter forçado o retorno do rei à Europa, pudesse submetê-los à escravidão e aumentar o poder das autoridades locais, que não encontrariam limites no abuso de sua mão de obra e no avanço sobre suas terras. Em 1822, a antiga junta de governo, adepta ao constitucionalismo de Portugal, reprimiu com violência dois motins indígenas em Vila Viçosa e Maranguape (cf. Xavier, 2015, p.82-98; Costa, 2016, p.121-144, 251-259). Tais casos mostram que o antilusitanismo popular e os conflitos dele decorrentes se manifestavam a partir de conjunturas particulares. Como afirma Gladys Ribeiro acerca dos conflitos de rua antilusitanos no Rio de Janeiro, "tinham muito mais um conteúdo racial e 'patriótico', sem serem nacionalistas” (Ribeiro, 1997, p.312).

Em 1824, o "ódio aos portugueses" por parte dos índios foi aproveitado pela presidência do Ceará para estreitar os laços com essas comunidades. Em 31 de maio, Gonçalves ordenou ao juiz ordinário de Soure que executasse a prisão dos “europeus Francisco dos Santos, Custódio José de Almeida e Alberto Antônio Lopes ... e imediatamente os fará processar", em atendimento à "denúncia inclusa da oficialidade e mais índios dessa vila por corpo de delito". 5 Por ainda viverem no Brasil em 1824, esses três portugueses provavelmente não tinham se submetido às Cortes de Lisboa em 1822. Entretanto, ainda que tivessem apoiado o projeto da independência do Brasil, é provável que sua convivência com os naturais da América, ao longo desse período, não tenha sido pacífica. $\mathrm{O}$ rápido atendimento da denúncia indígena também atingia os já comentados anseios da presidência em consolidar sua relação com essas comunidades, buscando conciliar os objetivos de cada um em torno do mesmo inimigo: o absolutismo português.

Vendo o caso por outro ângulo, a atribuída agressão dos portugueses contra os índios pode nos fornecer mais elementos. Denis Bernardes chamou a atenção para o antilusitanismo popular que se materializou "em manifestações de violência, seja individual ou coletiva, contra potenciais suspeitos de apoiar a recolonização do Brasil" (Bernardes, 2011, p.148). Mas o caso de Soure mostra que os índios, assim como outras classes populares, também poderiam ser alvo de ataques. Além do antilusitanismo indígena, a denúncia revela que o apreço do governo por essa população não era compartilhado por todos, muito menos pelos proprietários que viviam em Fortaleza e nas vilas do entorno. Para esses, os índios não passavam de mão de obra barata, semelhantes aos escravos, por quem nutriam não mais que desprezo. 
Gonçalves, sem querer se desfazer desses importantes aliados (pelo menos no quesito bélico), teve de lidar com essas tensões. Em circular aos comandantes de ordenanças da província, o presidente ordenou que cada soldado estivesse municiado de arcos e flechas, como forma de contornar o problema da falta de armamentos em meio a um ataque externo iminente. "Estou antevendo que os meus patrícios e concidadãos objetarão que não são caboclos; eu responderei que nós todos temos por brasão o arco e a flecha, e mesmo lhe darei o exemplo quando a necessidade o pedir. Não escute vossa mercê escusa alguma, e faça cumprir exatamente este ofício". ${ }^{6} \mathrm{O}$ "arco e flecha" serviriam para os não índios, nesse contexto, apenas como brasão, símbolo de patriotismo, que poderia se expressar na memória de lideranças do passado ou mesmo em seus nomes, mas não necessariamente instaurando uma relação de igualdade com os índios vivos, pejorativamente chamados de "caboclos".

O presidente, em contrapartida, buscava remediar diversos problemas de uma só vez. Primeiramente, chamava os índios de "irmãos" e "valorosos patrícios" pela necessidade de construir com eles uma boa relação, tendo em vista sua importância militar. Evaldo Cabral de Mello destaca que a presença indígena nas tropas realistas foi fundamental porque faziam "a guerra do país" guerrilha nas matas - ao passo que os confederados apenas conheciam "a dos europeus ou portugueses” - ou seja, em campo aberto (Mello, 2004, p.233). Por isso Gonçalves, na mesma circular aos comandantes das ordenanças, buscou convencê-los de que uma "flecha despedida de uma mão destra faz quase tanto estrago como a bala vomitada das granadeiras ... porque alcançam de longe, e por entre os matos ofendem ao inimigo e defendem o atirador”. Não podiam, portanto, "apresentar batalha em campo raso, e a grande vantagem leva[vam] das guerrilhas e dos caçadores". ${ }^{7}$ Conhecendo o potencial dos índios na guerra, o presidente visava, em segundo lugar, solucionar o problema da falta de armamentos implementando as táticas indígenas nas outras tropas.

Consolidando sua aliança com os índios, fazendo-os conviver com os outros patrícios e contornando a carência de estrutura bélica, o governo do Ceará protegeria a província das ameaças que julgava vir dos supostos conluios entre Pedro I e Portugal, intensificadas no mês de julho (cf. Mello, 2004, p.203204; Bernardes, 2011, p.148). No dia 2, pela falta de posicionamento da Coroa a respeito das exigências constitucionalistas, Manuel de Carvalho Paes de Andrade proclamou a Confederação do Equador no Recife. Segundo Cabral de Mello, não se tratava, entretanto, de uma "alternativa ao Brasil”, mas de uma 
proposta de união federal flexível entre as províncias, contrária ao centralismo do Estado (Mello, 2004, p.211-214). ${ }^{8}$

Enquanto a notícia ainda não havia sido recebida no Ceará nem se organizava um posicionamento por parte do governo, Tristão Gonçalves continuava a conclamar os habitantes da província a se oporem às ameaças externas. Entre os indígenas os contatos se deram de maneira semelhante, mas a definição do "inimigo" não era tão clara. Em 21 de julho, o presidente respondeu a um ofício da câmara dos índios de Arronches do dia 15 agradecendo suas "expressões de amizade". Assegurou que até o fim conservaria seus sentimentos patrióticos "sem duvidar jamais da probidade dos valorosos brasileiros da vila de Arronches". Alertou-os que, se quisessem ser escravos, que assinassem o projeto de Constituição, mas quanto a ele "e aos liberais", com armas na mão, preferiam morrer mil vezes do que assinar "uma só vez o selo abominável do servilismo". Contava, portanto, com a fidelidade dos vereadores da vila e dos índios que lá viviam, "esses miserandos despojos do furor europeu”. Por fim, ordenou à Câmara que procedesse à promoção dos oficiais indígenas e convidou que cada um fosse "obter (grátis) o seu título da secretaria deste governo", bem como ao escrivão, que mandasse "requerer da secretaria deste governo (grátis) a sua provisão". ${ }^{9}$

Não há nesse ofício nenhuma referência ao imperador. O inimigo é apontado indefinidamente como o "furor europeu", que despojara os índios ao longo de toda a colonização. Em contrapartida, Gonçalves identificava os índios com o termo brasileiros, destacado em itálico no original, e associava novamente o projeto de Constituição à escravidão. O uso cuidadoso das palavras buscava mais uma vez construir uma relação estável com os indígenas, sem ofender o imperador - que historicamente haviam defendido - e denunciando o autoritarismo do governo central. Completando seu argumento com a oferta gratuita de títulos - ancorando-se no apreço indígena pelas patentes militares - o presidente visava solidificar ainda mais a adesão dos índios aos liberais e sua amizade recíproca, como se infere pelo início do ofício.

A aliança indígena com o grupo de Tristão Gonçalves e Pereira Filgueiras não se dava pela conversão dos índios ao liberalismo. Em um primeiro momento, entre a repressão aos motins de Maranguape e Viçosa e a deposição da terceira junta governativa em 1822, os "liberais" eram representados especialmente pela elite de Fortaleza. Apoiando-se nas ideias vindas da Europa, as autoridades da capital visavam adquirir cada vez mais poder, configurando-se em grande ameaça às garantias das comunidades indígenas. Curiosamente, os 
novos "liberais" de 1824 eram, em 1822, os defensores do absolutismo. Como afirma Julio Sánchez Gómez, as disputas entre "conservadores" e "liberais" desse período tinham pouco de ideológico e muito de luta pela terra e pelo controle sobre as populações provinciais (Sánchez Gómez, 2009, p.267). Em termos locais, a postura dos índios se definiu a partir de demandas cotidianas e das particularidades do contexto. Em 1824, se a Câmara de Fortaleza apoiava as medidas do imperador com o objetivo de barrar o poderio do interior, para os índios era mais sensato ficar ao lado dos "liberais" de então que, desde o ano anterior, davam provas de boa vontade, ou, pelo menos, de que atenderiam às suas expectativas. ${ }^{10}$

Até então, a correspondência entre o governo cearense e as autoridades nas vilas de índios aqui analisada não atacava diretamente a figura do imperador. Contudo, as lideranças indígenas certamente sabiam do posicionamento dos liberais e, apesar da sua histórica relação de fidelidade à monarquia, mantiveram-se aliadas a eles. As ações de Tristão Gonçalves em benefício aos índios oficiais de ordenanças sinalizavam que o liberalismo pregado por ele e por seus correligionários não atingiria negativamente as garantias conquistadas durante o Antigo Regime.

A postura de pelo menos parte das lideranças indígenas foi confirmada com a sessão que proclamou a adesão do Ceará à Confederação do Equador em 26 de agosto de 1824. Reunindo autoridades do governo da província, de várias vilas e das câmaras do Aquiraz e de Messejana, os presentes denunciaram os "perjúrios de dom Pedro, príncipe de Portugal (chamado imperador do Brasil)", que desrespeitara o "pacto social" e os "foros da liberdade". O soberano teria cometido ações autoritárias como a dissolução da Constituinte, construindo "por si, como se viu, do infame projeto de constituição, que não só deu, mas também mandou arbitrariamente jurar por todas as câmaras das províncias do Brasil, reputando-nos escravos ou propriedade sua”. Por isso, foi acusado de pretender sujeitar os brasileiros "novamente ao domínio português, não cumprindo assim as condições essenciais pelas quais havia subido ao trono". Por fim, foi proposta a criação de um Grande Conselho no Ceará - a exemplo do que se fizera em Pernambuco - e o presidente eleito, Tristão Gonçalves de Alencar Araripe, jurou fidelidade "à confederação do Equador, que é a união das quatro províncias ao norte do cabo de Santo Agostinho, e as demais que para o futuro se forem unindo". Em seguida todos prestaram juramento, prometendo fazer guerra ao despotismo imperial que pretendia "escravizar-nos e obrigar-nos a fazer união do Brasil com Portugal". ${ }^{11}$ 
A historiografia cearense que abordou a sessão de 26 de agosto de 1824 destacou as denúncias contra a tendência absolutista de Pedro I e seus planos de unir-se a Portugal para recolonizar o Brasil (cf. Pinto, 1899, p.40; Câmara, 1924, p.321-322; Studart, 1924a, p.620; Girão, 1984, p.138; Felix, 2010, p.106108). Não foi sequer mencionada, contudo, a presença de representantes das vilas de índios da província, como Mathias Alves de Figueiredo Rocha, José da Rocha Mota, José Felix de Freitas e Paulo Fontanelas, procuradores, respectivamente, das câmaras de Arronches, Soure, Baturité (a mesma Monte-mor Novo) e Vila Viçosa. Além deles, em meio às mais de quatrocentas assinaturas, é possível identificar a de, pelo menos, quatro índios: Francisco da Costa Lira (capitão-mor de Soure), Atanásio Faria Maciel (capitão-mor, juiz de fora e presidente da Câmara de Messejana), Vitorino Correa da Silva "Parangaba" ("capitão-mor e eleitor" de Arronches) e João da Costa da Anunciação ("sargento-mor e eleitor” de Vila Viçosa). ${ }^{12}$

A presença tão significativa de lideranças indígenas indica uma mudança de perspectiva no posicionamento político dos índios, cuja tendência à defesa da monarquia foi bastante comentada pela historiografia mais recente. Os motivos para essa nova postura estavam ligados aos principais argumentos levantados na sessão de adesão do Ceará à Confederação: a associação entre as atitudes autoritárias de Pedro I e os supostos planos recolonizadores portugueses. Para os índios, desde 1821, Portugal passou a significar uma ameaça às suas liberdades, como se de lá viessem intenções de novamente submetê-los à escravidão, assim como haviam sofrido seus antepassados. ${ }^{13}$ Por isso é curioso o acréscimo de "Parangaba" que o capitão-mor de Arronches Vitorino Correa da Silva fez ao seu nome. Apesar da contradição costumeira dos brancos desse período, o capitão Vitorino, sem medo de se associar aos costumes "bárbaros" dos ancestrais, fez referência ao antigo nome de sua vila - aldeia da Parangaba - como forma de se opor a qualquer ação escravizadora que viesse de fora.

A adesão à Confederação do Equador se seguiu pelas câmaras da província, e há pelo menos um registro de sessão de juramento feita por vereadores de uma vila de índios. Apenas no dia 10 de outubro, a Câmara de Monte-mor Novo reuniu seus membros e diversas outras pessoas do município para declarar apoio ao ato sufragado em Fortaleza no mês de agosto. Entre as assinaturas, que não traziam qualquer informação sobre ocupação profissional ou origem étnica, a única que identifiquei ser de um indígena é a do sargento-mor Manoel José da Rocha. A ata da sessão não faz nenhuma referência ao fato de a vila ser 
de índios, ${ }^{14}$ mesmo porque, no início do século XIX, a maior parte da população de Monte-mor Novo, bem como de sua Câmara municipal, era de extranaturais. ${ }^{15}$

É de se questionar, portanto, o quanto o juramento do sargento-mor Rocha, ou o de outros indígenas mencionados anteriormente, representavam os anseios da maioria dos índios de Monte-mor Novo e de outras vilas da província. Não temos acesso às opiniões daqueles que não ocupavam postos militares ou de câmara, mas a presença de oficiais índios em sessões de tal importância indica o direcionamento político das lideranças indígenas. À frente de suas comunidades, posicionavam-se favoravelmente ao grupo que, naquele momento, governava a província, por conta das perspectivas de respeito às suas garantias e das ameaças tidas como recolonizadoras e escravizadoras.

\section{“De GRANDE Préstimo NA RESTAURAÇÃo da ORDEM"}

Enquanto o governo do Ceará aderia à Confederação do Equador, o território sob domínio do movimento sofria com a investida contrarrevolucionária por ordem de Pedro I. Ainda em julho a região da bacia do rio do Peixe, na fronteira da Paraíba com o Ceará, recebera ocupação dos regimentos imperialistas (cf. Studart, 1924b, p.149-150). Em agosto, já estavam presentes no litoral pernambucano as forças fieis à Coroa, lideradas pelo brigadeiro Francisco de Lima e Silva e pelo lorde inglês Thomas Alexander Cochrane, que lutava à época a serviço do governo brasileiro. No dia 12 de setembro entraram no Recife, e em outubro já se encontravam em Mossoró, no Rio Grande do Norte, próximo à divisa cearense. Sabendo que a vila do Aracati havia sido tomada, Tristão Gonçalves partiu acompanhado de uma tropa de índios em 12 de outubro, conseguindo recuperá-la ao domínio confederado no dia 18 (cf. Pinto, 1899, p.42; Galvão, 1914, p.64; Studart, 1924a, p.621; Felix, 2010, p.108). ${ }^{16}$

Entretanto, nesse mesmo dia, a armada de lorde Cochrane ancorava em Fortaleza, rendendo o governo da província - deixado por Gonçalves a cargo de José Felix de Azevedo e Sá - e, de acordo com a historiografia, hasteando sem qualquer resistência a bandeira imperial (cf. Pinto, 1899, p.44; Jaguaribe, 1918, p.51; Câmara, 1924, p.330; Studart, 1924a, p.616; Girão, 1984, p.139; Felix, 2010, p.109). Com a tranquila rendição, o então presidente Azevedo e Sá - perdoado e autorizado a continuar no cargo por Cochrane - ordenou ao 
sargento-mor indígena João da Costa da Anunciação - que estivera presente na sessão de adesão do Ceará à Confederação do Equador - que fizesse "congregar todos os índios seus subordinados" e os pusesse em marcha "logo e logo para esta capital”, comandados por ele. Lá encontrariam o presidente "pronto para defender os sagrados direitos de S. M. I. [Sua Majestade Imperial] o Sr. dom Pedro I Imperador Constitucional e Defensor Perpétuo deste Império". ${ }^{17}$

Sem mais explicações, as ordens dirigidas a Anunciação devem tê-lo deixado, no mínimo, intrigado. Não sabemos qual foi a reação do sargento de Vila Viçosa, mas a convocação de sua tropa já indicava o pleno estabelecimento do poder imperial em Fortaleza e a importância de se ter a força militar indígena na defesa dos interesses de Pedro I. A medida inesperada, contudo, nos faz refletir, por um lado, sobre a inviabilidade militar daquelas províncias para resistir ao governo central e, por outro, se havia de fato obstinação por parte dos aliados de Araripe em continuar com esse projeto.

Nos relatos que escreveu acerca de suas atividades no Brasil, Cochrane contou como se deu a negociação para a tomada da capital cearense (cf. Jaguaribe, 1918, p.48). Após o hasteamento da bandeira imperial, o lorde mandou que se "oficiasse a todas as partes da província, anunciando o regresso da cidade à obediência". Mandou comunicações às forças revolucionárias "cujas tropas abandonaram todas", e mesmo o "corpo sob o comando imediato do presidente revolucionário Araripe [que se encontrava no Aracati] foi reduzido a cem homens - até os índios, sem exceção, abandonando o seu estandarte". Atribuiu o sucesso da pacificação da província à anistia geral que ofereceu à população, inclusive ao próprio Tristão Gonçalves, "remonstrando-lhe (sic) sobre a loucura da carreira que estava prosseguindo". Prevendo a negativa do liberal e sua consequente fuga para o interior - o que realmente ocorreu em 20 de outubro -, Cochrane ofereceu

a quem o apreendesse recompensa suficiente para induzir os índios que antes haviam sido seus sustentadores a partir em busca dele, resultando a vir a ser morto, e todos seus sequazes apreendidos. Os chefes indianos (sic), assim como a gente que deles dependia, foram de grande préstimo na restauração da ordem, combinando robustez corporal superior com atividade, energia, docilidade, e força de aturar que nunca falhava - formando, com efeito, os melhores padrões da raça nativa que eu vira na América do Sul. (Cochrane, 1856, p.184-185) 
O relato de Cochrane permite mais uma vez perceber a importância militar que tinham as tropas indígenas para a manutenção do governo de Tristão Gonçalves. A mesma valia foi percebida pelo lorde inglês, fazendo dessa população peça fundamental para o restabelecimento do poder imperial. Em contrapartida, os índios viram naquele momento que a aliança com a Armada de Cochrane e a retomada dos laços de fidelidade com a Coroa eram o melhor caminho. A aceitação da "recompensa" - que o lorde não deixou claro do que se tratava - mostra que a rendição de Fortaleza ocorreu também pelas vantagens vislumbradas pelas lideranças, inclusive as indígenas. Mas apenas isso foi suficiente para que os índios rompessem uma relação tão estreita, da qual dependia o futuro de suas comunidades, a ponto de passarem de "sustentadores" a "perseguidores" do liberal?

Em 21 de outubro, 3 dias depois da adesão de Fortaleza às forças imperiais, o presidente Azevedo e Sá ordenou ao capitão Manoel Cavalcante que convocasse "os índios da vila de Arronches, e depois de ler-lhes o ofício de Cochrane de 18 de outubro do corrente", que os enviasse para a capital. ${ }^{18} \mathrm{~A}$ Plácido Fontenelle, de Vila Viçosa, comunicou no dia 23 que Pedro I já havia sido aclamado imperador constitucional e defensor perpétuo do Brasil, e que mandava "pela segunda vez ao capitão-mor e diretor dos índios dessa vila" que os fizesse marchar para a capital. ${ }^{19}$ Inteirou João da Costa da Anunciação das ordens que passara "a todas as câmaras e autoridades constituídas afim desta província de jurarem e prestar obediência e fidelidade ao Augusto Sr. dom Pedro de Alcântara". ${ }^{20}$

Não consegui encontrar o ofício de Cochrane aos índios. A ação de contatá-los, no entanto, mostra que os motivos reais da mudança de lado indígena provavelmente iam muito além da recompensa oferecida. As transformações que o cenário político lhes impunha não deixavam de estar vinculadas às suas perspectivas para o futuro. A necessidade de uma segunda ordem ao sargento Anunciação indica que as novidades não devem ter sido facilmente digeridas. Contudo, diante da superioridade bélica da Armada que dominara tão rapidamente Fortaleza, resistir poderia representar um suicídio, e a anistia, somada à recompensa oferecida, possibilitava uma nova representação para a figura de Pedro I.

No início de novembro de 1824 , aquele que havia pouco tempo era tido como um déspota recolonizador a serviço de Portugal já era aclamado em toda a província, e seus últimos inimigos eram perseguidos. Tristão Gonçalves, após o abandono de sua tropa - dentre eles, os índios - fugira para o sertão do 
Jaguaribe, onde foi assassinado no dia 31 de outubro (cf. Pinto, 1899, p.42; Studart, 1924b, p.160; Câmara, 1924, p.333; Girão, 1984, p.139; Felix, 2010, p.110). Em 3 de novembro, a Câmara de Monte-mor Novo, tendo conhecimento dos acontecimentos de 18 de outubro, "visto que as tropas se achavam destroçando o povo e da mesma sorte derribando suas moradas", juraram fidelidade ao imperador, constando também a assinatura do sargento-mor indígena Manoel José da Rocha. ${ }^{21}$

A demora na reação da vila - que ficava apenas a cerca de 100 quilômetros de Fortaleza, ou seja, possivelmente não tardara em saber da ação de Cochrane - pode indicar que a adesão de algumas câmaras no interior da província tenha sido muito mais por medo do que por reais e instantâneos sentimentos de fidelidade ao imperador. No dia 8 de novembro, o presidente ordenou ao comandante de Vila Viçosa e Ibiapina que mandasse "destroçar toda a tropa de índio do seu comando" que mandara "reunir e marchar para esta capital pelo meu ofício de 19 do mês passado". A marcha já não era mais necessária "visto que se acha[va] esta capital e província em tranquilidade pela morte do tirano Tristão Gonçalves ... e outros sequazes republicanos, tão infiéis como desobedientes ao Augusto Imperador Defensor Perpétuo do Brasil". ${ }^{22}$ Se, passado um mês, a ordem para o deslocamento das tropas de índios da Ibiapaba ainda não havia sido cumprida, a nova situação política do Ceará não foi recebida com a aceitação passiva de que Gonçalves era um tirano. Mas a rápida tomada da capital e a morte do antigo líder eram sinais claros de que não havia mais condições para resistir.

O inimigo vitorioso, no entanto, não eram apenas as forças imperiais. Keile Felix argumenta que a escolha de Fortaleza como sede do poder no Ceará visava barrar o grande poderio local que as elites do interior da província construíram ao longo de todo o período colonial. Nessa luta entre o "litoral" e o "sertão", a "escolha de Fortaleza como local sede do poder se coaduna justamente com a tentativa de retirar desse sertão 'insubordinado’ o poder de mando que usufruíam" (Felix, 2010, p.111-112). O hasteamento da bandeira imperial representava, portanto, a vitória da capital, que não era mais comandada por lideranças do interior.

A aceitação da mudança na situação política do Ceará por parte dos índios e de outros grupos da província não foi necessariamente fácil, como vimos pela relativa demora nas respostas da Câmara de Monte-mor Novo e da tropa indígena de Vila Viçosa. Entretanto, para os índios, o poder ocupado pela elite de Fortaleza estava, agora, centralizado nas mãos do monarca. Por isso, no caso 
aqui analisado, ao aceitar a soberania de Pedro I, os índios evitavam o massacre pelas forças imperiais, ao mesmo tempo que viam garantidas suas terras e outros benefícios.

As ações de apaziguamento das companhias indígenas prosseguiram em novembro: no dia 9, Azevedo e Sá expediu aos índios “ordens a destronarem para as suas habitações, visto não se precisarem mais reunidas”. Ao sargento-mor José Felix de Mendonça, com quem até aquele momento os indígenas estavam reunidos, recomendara que os "fizesse ver quanto bem resultará sempre da tranquilidade e paz em que devemos todos viver". ${ }^{23}$ Pelo que expôs o presidente, deve ter havido alguma necessidade de convencimento para que a tropa de índios - que, pelo menos até outubro, estava no Aracati - aceitasse o novo contexto político. Já em Monte-mor Velho, o governo encontrou alguma resistência para impor a ordem. Em 11 de novembro, Azevedo e Sá comunicou ao diretor da povoação que havia tomado providências em relação ao índio José Francisco do Monte, "para evitar o mal que ele causa[va] a esses povos tranquilos", e ordenou que os índios voltassem aos seus roçados. ${ }^{24}$ No mesmo dia ordenou ao comandante de Monte-mor Velho que não se descuidasse do referido índio, devendo "procurar manter a boa ordem nesses povos". ${ }^{25}$ Apesar do reinado definitivamente centralizado que Pedro I passaria a exercer, o contexto posterior a 18 de outubro não tranquilizou facilmente a todos os índios.

De acordo com Antônio Pereira Pinto, após o "encerramento da revolta no Ceará, à anarquia promovida pelos revolucionários sucedeu a anarquia das classes baixas da província, que acobertadas com o manto da legalidade cometeram toda a casta de atentados" (Pinto, 1899, p.44). Por isso as ações das tropas indígenas foram tão necessárias, como já tínhamos visto no relato de Cochrane. Apesar das divergências internas, a maioria dos índios, ainda que discordassem, não tiveram como se opor à conjuntura que se desenhava e passaram a agir em prol dos interesses imperiais, do estabelecimento da ordem e da perseguição aos liberais fugitivos.

Em 19 de novembro, Azevedo e Sá enviou uma tropa de "300 praças militares e 200 índios”, sob o comando de José Felix de Mendonça, ao Aracati, para se reunirem ao regimento de Luis Rodrigues Chaves. Seu objetivo era encontrar o liberal José Gomes do Rego, o Cazumbá, que fugira de Pernambuco, a fim de se conhecer suas intenções em território cearense. ${ }^{26}$ No mesmo dia, ordenou ao almoxarife dos armazéns nacionais e imperiais de Fortaleza para dar assistência aos índios de Vila Viçosa, que somavam de 300 a 400 praças e lá ficariam por 5 dias, fornecendo-lhes "quatro matolages (sic) e seis alqueires 
de farinha por dia". ${ }^{27} \mathrm{Em} 22$ de novembro, em resposta a um ofício do sargento-mor Mendonça, mandou soltar o capitão-mor indígena de Arronches que estava preso - de cujo nome disse não saber - e o levasse na expedição. ${ }^{28} \mathrm{O}$ presidente provavelmente não conhecia sequer o motivo da punição ao capitão-mor, mas a necessidade de manter a ordem era urgente. A prisão de tal liderança indígena é mais uma prova de que divergências internas ocorreram, mas não impediram que a maioria da população e das tropas de índios se mantivesse obediente ao imperador e ao governo de Fortaleza.

Já em janeiro de 1825, duzentos índios de Viçosa foram mobilizados para a vila de Granja com o objetivo de capturar o coronel João de Andrade Pessoa Anta. O historiador João Brígido contou que, no dia 22, os indígenas "se dispersaram pelas ruas e cometeram toda sorte de violências, saqueando e açoitando homens e mulheres, até de famílias importantes. Dezenove pessoas sofreram esse vilipêndio". As "mais importantes da vila" fugiram, e "após isto os índios tomaram quartel na casa da câmara”. O grupo só teria se tranquilizado depois que Joana da Mota "tratou de ganhar o sargento-mor dos índios, chefe ostensivo deles, com fazendas e quinquilharias. Eles eram, na verdade, comandados por Gonçalo Luiz de Carvalho, inimigo rancoroso de Andrade pelo fato de este o haver processado por furto de gados". ${ }^{29}$

Passando a imagem de desordeiros aos índios sem citar fontes - construindo seu texto a partir de relatos de sobreviventes do confronto -, Brígido não informou qual seria a relação deles com Carvalho. Independentemente de haver de fato tal contato, o autor não observou que no início de janeiro de 1825 os índios já estavam, havia muito tempo, a serviço das determinações imperiais e em caça aos liberais. Além disso, as confusões decorrentes da perseguição a Pessoa Anta não eram fatos isolados: o comandante das armas Conrado Jacob de Niemeyer relatou ao presidente Azevedo e Sá, em setembro de 1825, "que os índios de Vila Viçosa [eram] insolentes, que os anarquistas da Granja não sossega[vam] e [estavam] em contínua rivalidade com os ditos índios”. ${ }^{30}$

A tensa situação da perseguição de Pessoa Anta foi um fragmento de um contexto muito mais complexo do que supôs João Brígido. A "anarquia das classes baixas” citada por Pereira Pinto revelava intensa insatisfação popular que, com o fim da Confederação do Equador, expressou sua fidelidade ao imperador e sua revolta contra as elites locais ambiciosas por poder. Apesar da relutância da tropa de João da Costa da Anunciação após o hasteamento da bandeira imperial, como vimos anteriormente, os índios de sua vila também se envolveram em conflitos contrários às "famílias mais importantes", de onde 
vinham muitos "patriotas" ou "anarquistas". Por mais que tivessem os mesmos inimigos das autoridades imperiais, as causas de sua aversão aos "ricos liberais" e as formas de combatê-los eram próprias.

\section{CONSIDERAÇÕES FINAIS}

No período posterior à Confederação do Equador, a elite de Fortaleza passou a assumir o comando da então província, havia muito ambiciosa das terras dos indígenas e do usufruto ilimitado dessa mão de obra. Diante da mudança na conjuntura política do Ceará com a queda da Confederação, parecia não haver saída para os índios, a não ser manifestar apoio a Pedro I.

Segundo Bernardes, à época da Confederação do Equador, os chefes indígenas, "com alguma razão, viam na Coroa a garantia da posse de suas terras e da legitimação de uma hierarquia de poder da qual se sentiam parte" (Bernardes, 2011, p.165-166). Em outubro de 1824, apoiar o juramento de Fortaleza à Constituição imperial não era uma opção agradável para os índios, mas era a melhor possível, tendo em vista que Pedro I "moderaria" a atuação dessas autoridades. Com sua partida do Brasil, o poder das elites locais não encontrou barreiras para usurpar o que pudesse das comunidades dos indígenas. Estes, em contrapartida, reagiram como puderam. Alguns índios da Ibiapaba, revoltados com os recrutamentos forçados, juntaram-se em 1839 a uma rebelião bem mais longa do que a tratada aqui: a Balaiada (cf. Xavier, 2015, p.156-161; Costa, 2016, p.313-335).

\section{REFERÊNCIAS}

BERNARDES, Denis Antônio de M. A gente ínfima do povo e outras gentes na Confederação do Equador. In: DANTAS, Mônica Duarte (Org.) Revoltas, motins e revoluções: homens livres e libertos no Brasil do século XIX. São Paulo: Alameda, 2011.

BRÍGIDO, João. Biografias: coronel João de Andrade Pessoa Anta. Revista do Instituto do Ceará, Fortaleza: Tipografia Econômica, tomo III, 1889.

CÂMARA, João Eduardo Torres. A Confederação do Equador em 1824 e revolução, que a produziu, como consequência da dissolução da nossa primeira constituinte a 12 de novembro de 1823 e jamais de intuitos ou ideias separatistas. A ação de um de seus chefes, o futuro senador Alencar, decisiva a abril de 1831, para a manutenção do império e com este talvez a da unidade nacional. Revista do Instituto do Ceará, Fortaleza: Tipografia Gadelha, tomo especial, 1924. 
CARVAlHO, Antônio R. de. Memória sobre a capitania do Ceará no ano de 1816. Publicações do Arquivo Nacional, Rio de Janeiro: Oficina Gráfica do Arquivo Nacional, n.XXIV, 1929.

CARVALHO, Marcus J. M. de. Os índios e o Ciclo das Insurreições Liberais em Pernambuco (1817-1848): Ideologias e Resistências. In: ALMEIDA, Luiz Sávio de; GALINDO, Marcos. Índios do Nordeste: temas e problemas - III. Maceió: Edufal, 2002.

COCHRANE, Thomas Alexander. Narrativa de serviços no libertar-se o Brasil da dominação portuguesa. London: James Ridgway, 1856.

COSTA, João Paulo Peixoto. Na lei e na guerra: políticas indígenas e indigenistas no Ceará (1798-1845). Tese (Doutorado em História) - IFCH, Universidade Estadual de Campinas (Unicamp). Campinas, 2016.

DANTAS, Mariana Albuquerque. Dimensões da participação política indígena na formação do Estado nacional brasileiro: revoltas em Pernambuco e Alagoas (18171848). Tese (Doutorado em História) - Universidade Federal Fluminense (UFF). Niterói, 2015.

FELIX, Keile Socorro Leite. "Espíritos inflamados": a construção do Estado nacional brasileiro e os projetos políticos no Ceará (1817-1840). Dissertação (Mestrado em História) - Universidade Federal do Ceará (UFC). Fortaleza, 2010.

GALVÃO, Sebastião de Vasconcelos. Confederação do Equador: 24 de julho de 1824. Revista do Instituto do Ceará, Fortaleza: Tipografia Minerva, tomo XXVIII, 1914. GIRÃO, Raimundo. Pequena história do Ceará. Fortaleza: Ed. UFC, 1984.

JAGUARIBE, Domingos. Notas para a história das repúblicas de 1817 e 1824. Revista do Instituto do Ceará, Fortaleza: Tipografia Minerva, tomo XXXII, 1918.

KOSTER, Henry. Viagens ao Nordeste do Brasil. Rio de Janeiro/São Paulo/Fortaleza: ABC Ed., 2003.

MARTINS, Vicente. Pessoa Anta (biografia). Revista do Instituto do Ceará, Fortaleza: Tipografia Minerva, tomo XXXI, 1917.

MELLO, Evaldo Cabral de. A outra independência: o federalismo pernambucano de 1817 a 1824. São Paulo: Ed. 34, 2004.

NOGUEIRA, Paulino. Presidentes do Ceará, primeiro reinado. $1^{\circ}$ presidente: coronel Pedro José da Costa Barros. Revista do Instituto do Ceará, Fortaleza: Tipografia Econômica, tomo IV, 1890.

PEIXOTO, Eduardo Marques. Ceará: movimento político de 1824. Revista do Instituto do Ceará, Fortaleza: Tipografia Minerva, tomo XXI, 1907.

PINTO, Antônio Pereira. A Confederação do Equador por Antônio Pereira Pinto na parte relativa ao Ceará. Revista do Instituto do Ceará, Fortaleza: Tipografia Studart, tomo XIII, 1899.

RIBEIRO, Gladys Sabina. A liberdade em construção: identidade nacional e conflitos antilusitanos no Primeiro Reinado. Tese (Doutorado em História) - Universidade Estadual de Campinas (Unicamp). Campinas, 1997. 
SÁNCHEZ GÓMEZ, Julio. Invisibles y olvidados: indios e independencia de Brasil. Studia Historica. Historia Contemporánea, n.27, p.235-277, 2009.

STUDART, Guilherme. O movimento republicano de 1824 no Ceará. Revista do Instituto do Ceará, Fortaleza: Tipografia Gadelha, tomo especial, 1924a.

. Parte Cronológica. Revista do Instituto do Ceará, Fortaleza: Tipografia Gadelha, tomo especial, 1924b.

XAVIER, Maico Oliveira. Extintos no discurso oficial, vivos no cenário social: os índios do Ceará no período do império do Brasil - trabalho, terras e identidades indígenas em questão. Tese (Doutorado em História) - Universidade Federal do Ceará (UFC). Fortaleza, 2015.

Figura 1 - Locais de atuação dos índios do Ceará na Confederação do Equador

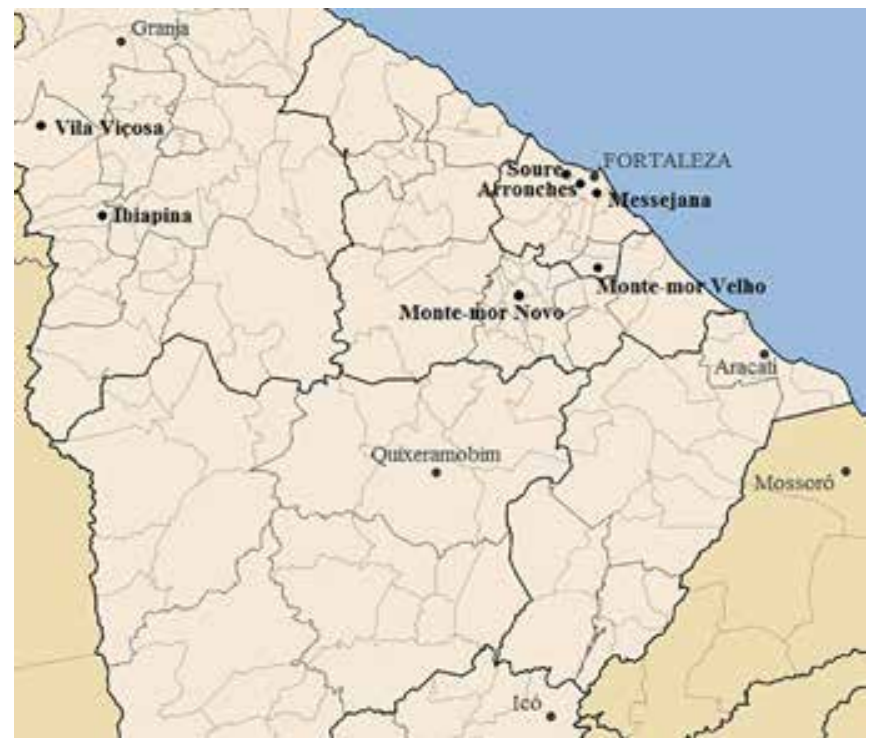

Marcações feitas pelo autor sobre cartografia atual do estado do Ceará, disponível em: https://pt.wikipedia.org/wiki/Ceará

\section{NOTAS}

${ }^{1}$ Cf. Alvará de 17 de março de 1823. Disponível em: http://www2.camara.leg.br/legin/fed/ alvara/anterioresa 1824/alvara-41119-17-marco-1823-575028-publicacaooriginal-98105-pe.html; Acesso em: 29 ago. 2016. 
${ }^{2} \mathrm{Na}$ ata da sessão de 29 de abril de 1824 do governo provisório do Ceará, que decidiu pela deposição do presidente nomeado Pedro José da Costa Barros, constam as assinaturas de Francisco Joaquim da Costa Lira e Vitorino Correia de Souza Parangaba. Cf. N. 12. ATA da sessão extraordinária de 29 de abril de 1824. Apud. Parte documental: documentos para a história da Confederação do Equador coligidos pelo Barão de Studart. Revista do Instituto do Ceará, Fortaleza: Tipografia Gadelha, tomo especial, 1924, p.376. O primeiro talvez seja o capitão-mor de Soure Francisco da Costa Lira, “de nação índio”, que prestou juramento em 17 de janeiro de 1821. Cf. Termo de juramento de Francisco da Costa Lira como capitão-mor de Soure. Fortaleza, 17 de janeiro de 1821. Arquivo Público do Estado do Ceará (APEC), série Governo da Capitania (GC), livro 61, p.82 e 83. O segundo nome guarda, no mínimo, semelhanças com o de Vitorino Correia da Silva, "homem índio e morador do termo ... de Arronches", que recebeu em 26 de dezembro de 1823 patente de capitão-mor de sua vila, antiga aldeia da Parangaba. Cf. Registro de patente de capitão-mor de Arronches a Vitorino Correa da Silva. Fortaleza, 26 de dezembro de 1823. APEC, GC, livro 72, p.120.

${ }^{3}$ De Tristão Gonçalves de Alencar Araripe aos diretores de Arronches, Soure, Messejana, Monte-mor Novo, Vila Viçosa, Almofala, Monte-mor Velho e São Pedro de Ibiapina. Fortaleza, 18 de maio de 1824. APEC, série Governo da Província (GP), Correspondências Expedidas (CO EX), livro 2, p.44. Diário do Governo do Ceará, Fortaleza, 2 de junho de 1824, nº 9 , p.1V. Arquivo Nacional (AN), série Confederação do Equador (IN), caixa 742, pac. 1.

${ }^{4}$ De Tristão Gonçalves de Alencar Araripe ao capitão-mor de Arronches. Fortaleza, 21 de maio de 1824. APEC, GP, CO EX, livro 2, p.50V. De Tristão Gonçalves de Alencar Araripe a Antônio José de Vasconcelos. Fortaleza, 21 de maio de 1824. APEC, GP, CO EX, livro 2, p.51. Diário do Governo do Ceará, Fortaleza, 2 de junho de 1824, nº 9, p.2. AN, IN, caixa 742 , pac. 1 .

${ }^{5}$ De Tristão Gonçalves de Alencar Araripe ao juiz ordinário de Soure. Fortaleza, 31 de maio de 1824. APEC, GP, CO EX, livro 2, p.70V-71.

${ }^{6}$ De Tristão Gonçalves de Alencar Araripe aos comandantes de ordenança. Fortaleza, 27 de maio de 1824. APEC, GP, CO EX, livro 2, p.64-65.

${ }^{7}$ De Tristão Gonçalves de Alencar Araripe aos comandantes de ordenança. Fortaleza, 27 de maio de 1824. APEC, GP, CO EX, livro 2, p.64.

8 "Sequer o título de Confederação do Equador pode ser acoimado de regionalista, em vista da tendência retórica a denominar o Brasil de Império do Equador" (MELLO, 2004, p.218).

${ }^{9}$ De Tristão Gonçalves de Alencar Araripe à câmara de Arronches. Fortaleza, 21 de julho de 1824. Diário do Governo do Ceará, Fortaleza, 30 de julho de 1824, no 15, p.1V. AN, IN caixa 742 , pac. 4 .

${ }^{10}$ Como, por exemplo, a libertação dos presos de Maranguape, em 1823, e a utilização de Arronches e Messejana como bases militares para a deposição do governo de Costa Barros 
apoiado pela câmara de Fortaleza - que talvez tenha aproximado ainda mais os liberais das lideranças indígenas destas vilas - em 1824.

${ }^{11}$ Os juramentos e o registro foram feitos no dia seguinte. ATA da sessão extraordinária e grande conselho provincial. Fortaleza, 27 de agosto de 1824. Apud. Confederação do Equador. Revista do Instituto do Ceará, Fortaleza: Tipografia Minerva, tomo XXV, 1911, p.292-294.

${ }^{12}$ ATA da sessão extraordinária e grande conselho provincial. Fortaleza, 27 de agosto de 1824. Apud. Confederação do Equador. Revista do Instituto do Ceará, Fortaleza: Tipografia Minerva, tomo XXV, 1911, p.295-299.

${ }^{13}$ Quando esteve no Ceará 14 anos antes da Confederação do Equador, Henry Koster observou a repugnância dos índios "no uso do vocábulo senhor", supondo "ter começado nos imediatos descendentes dos indígenas escravos e se haja perpetuado essa repulsa na tradição ... os indígenas com quem tenho conversado, e tenho visto muitos, parecem saber que seus ancestrais trabalharam como escravos" (KOSTER, 2003, p.178).

${ }^{14}$ ATA da sessão extraordinária da câmara de Monte-mor Novo, 10 de outubro de 1824 . APEC, CM, câmara de Monte-mor Novo, livro 54, p.124-129V. Apud. Parte documental: documentos para a história da Confederação do Equador no Ceará coligidos pelo Barão de Studart. Revista do Instituto do Ceará, Fortaleza: Tipografia Gadelha, tomo especial, 1924, p.412-415.

${ }^{15}$ Cf. CARVALHO, 1929, p.XXVIII. "Mapa da população da capitania do Ceará extraído dos que deram os capitães-mores no ano de 1813”. Biblioteca Nacional (BN), II-32, 23, 3.

${ }^{16}$ Domingos Jaguaribe afirma que Luís Rodrigues Chaves, enviado a Pernambuco com os índios, foi convencido a lutar pela causa contrarrevolucionária e comandou a invasão do Aracati que motivou a marcha de Tristão Gonçalves para retomá-la. Cf. JAGUARIBE, 1918, p.51. Entretanto, para Torres Câmara, Chaves seguiu para o Recife em maio, e os índios só estiveram no Aracati na companhia de Gonçalves (cf. CÂMARA, 1924, p.321329).

${ }^{17}$ De José Felix de Azevedo e Sá a João da Costa da Anunciação. Fortaleza, 18 de outubro de 1824. APEC, GP, CO EX, livro 1, p.26.

${ }^{18}$ De José Felix de Azevedo e Sá a Manoel Cavalcante. Fortaleza, 21 de outubro de 1824. APEC, GP, CO EX, livro 1, p.29V.

${ }^{19}$ De José Felix de Azevedo e Sá a Plácido Fontenelle. Fortaleza, 23 de outubro de 1824. APEC, GP, CO EX, livro 1, p.31V.

${ }^{20}$ De José Felix de Azevedo e Sá a João da Costa da Anunciação. Fortaleza, 23 de outubro de 1824. APEC, GP, CO EX, livro 1, p.32.

${ }^{21}$ ATA da sessão extraordinária da câmara de Monte-mor Novo, 3 de novembro de 1824 . Apud. Parte documental: documentos para a história da Confederação do Equador no Ceará coligidos pelo Barão de Studart. Revista do Instituto do Ceará, Fortaleza: Tipografia Gadelha, tomo especial, 1924, p.459-462. 
${ }^{22}$ De José Felix de Azevedo e Sá ao Comandante de Vila Viçosa e Ibiapina. Fortaleza, 8 de novembro de 1824. APEC, GP, CO EX, livro 1, p.65.

${ }^{23}$ De José Felix de Azevedo e Sá a Manuel Moreira Barros. Fortaleza, 9 de novembro de 1824. APEC, GP, CO EX, livro 1, p.70.

${ }^{24}$ De José Felix de Azevedo e Sá a José Rodrigues Pereira. Fortaleza, 11 de novembro de 1824. APEC, GP, CO EX, livro 1, p.79.

${ }^{25}$ De José Felix de Azevedo e Sá a Vicente Ferreira Ramos. Fortaleza, 11 de novembro de 1824. APEC, GP, CO EX, livro 1, p.79V.

${ }^{26}$ De José Felix de Azevedo e Sá a Luís Rodrigues Chaves. Fortaleza, 19 de novembro de 1824. APEC, GP, CO EX, livro 1, p.102. De José Felix de Azevedo e Sá a Manuel Antônio de Amorim. Fortaleza, 19 de novembro de 1824. APEC, GP, CO EX, livro 1, p.103V-105. De José Felix de Azevedo e Sá a José Felix de Mendonça. Fortaleza, 19 de novembro de 1824. APEC, GP, CO EX, livro 1, p.105-105V.

${ }^{27}$ De José Felix de Azevedo e Sá ao almoxarife dos armazéns nacionais e imperiais de Fortaleza. Fortaleza, 19 de novembro de 1824. APEC, GP, CO EX, livro 1, p.105.

${ }^{28}$ De José Felix de Azevedo e Sá a José Felix de Mendonça. Fortaleza, 22 de novembro de 1824. APEC, GP, CO EX, livro 1, p.114V.

${ }^{29}$ Uma das vítimas dos índios ainda era viva quando Brígido escreveu seu texto: o "patriota" José Tibúrcio de Almeida Fortuna, que teria levado "um ferimento de seta" (BRÍGIDO, 1889, p.66; MARTINS, 1917, p.290; STUDART, 1924, p.627).

${ }^{30}$ De Conrado Jacob de Niemeyer a José Felix de Azevedo e Sá. Fortaleza, 20 de setembro de 1825 . AN, IN, caixa 742 , pac. 4 e 5 .

Artigo recebido em 3 de julho de 2017. Aprovado em 14 de julho de 2017. 